\title{
Correction to: Thermal Plasma Spraying as a New Approach for Preparation of Zinc Biodegradable Scaffolds: A Complex Material Characterization
}

\author{
Jaroslav Čapek ${ }^{1} \cdot$ Jan Pinc $^{1,2}$ • Šárka Msallamová ${ }^{2}$. \\ Eva Jablonská $^{3} \cdot$ Petr Veřtát $^{1} \cdot$ Jiří Kubásek $^{2}$. \\ Dalibor Vojtěch ${ }^{2}$
}

Published online: 23 October 2019

(c) ASM International 2019

\section{Correction to:}

J Therm Spray Tech (2019) 28:826-841

https://doi.org/10.1007/s11666-019-00849-1

The authors cited Project No. 16-06110S in the acknowledgements of the article. Please note the correct project is Project No. 18-06110S of The Czech Science Foundation.
Publisher's Note Springer Nature remains neutral with regard to jurisdictional claims in published maps and institutional affiliations.

The original article can be found online at https://doi. org/10.1007/s11666-019-00849-1.

Jaroslav Čapek

jaroslav.l.capek@gmail.com; capekj@fzu.cz

1 Institute of Physics, Academy of Sciences of the Czech

Republic, v.v.i. (AS CR), Na Slovance 1999/2,

18221 Prague 8, Czech Republic

2 Department of Metals and Corrosion Engineering, University of Chemistry and Technology Prague, Technická 5, 16628 Prague 6, Czech Republic

3 Department of Biochemistry and Microbiology, University of Chemistry and Technology Prague, Technická 5, 16628 Prague 6, Czech Republic 